\title{
Tropical biomass burning smoke plume size, shape, reflectance, and age based on 2001-2009 MISR imagery of Borneo
}

\author{
C. S. Zender ${ }^{1}$, A. G. Krolewski ${ }^{2, *}$, M. G. Tosca ${ }^{1}$, and J. T. Randerson ${ }^{1}$ \\ ${ }^{1}$ Department of Earth System Science, University of California, Irvine, Irvine, CA 92697-3100, USA \\ ${ }^{2}$ University High School, 4771 Campus Drive, Irvine, CA 92612, USA \\ *now at: Harvard College, Harvard University, Cambridge, MA, 02138, USA
}

Correspondence to: C. S. Zender (zender@uci.edu)

Received: 22 September 2011 - Published in Atmos. Chem. Phys. Discuss.: 22 November 2011

Revised: 29 March 2012 - Accepted: 29 March 2012 - Published: 11 April 2012

\begin{abstract}
Land clearing for crops, plantations and grazing results in anthropogenic burning of tropical forests and peatlands in Indonesia, where images of fire-generated aerosol plumes have been captured by the Multi-angle Imaging SpectroRadiometer (MISR) since 2001. Here we analyze the size, shape, optical properties, and age of distinct fire-generated plumes in Borneo from 2001-2009. The local MISR overpass at 10:30 a.m. misses the afternoon peak of Borneo fire emissions, and may preferentially sample longer plumes from persistent fires burning overnight. Typically the smoke flows with the prevailing southeasterly surface winds at 3$4 \mathrm{~m} \mathrm{~s}^{-1}$, and forms ovoid plumes whose mean length, height, and cross-plume width are $41 \mathrm{~km}, 708 \mathrm{~m}$, and $27 \%$ of the plume length, respectively. $50 \%$ of these plumes have length between 24 and $50 \mathrm{~km}$, height between 523 and $993 \mathrm{~m}$ and width between $18 \%$ and $30 \%$ of plume length. Length and cross-plume width are lognormally distributed, while height follows a normal distribution. Borneo smoke plume heights are similar to previously reported plume heights, yet Borneo plumes are on average nearly three times longer than previously studied plumes. This could be due to sampling or to more persistent fires and greater fuel loads in peatlands than in other tropical forests. Plume area (median $169 \mathrm{~km}^{2}$, with 25 th and 75 th percentiles at $99 \mathrm{~km}^{2}$ and $304 \mathrm{~km}^{2}$, respectively) varies exponentially with length, though for most plumes a linear relation provides a good approximation. The MISR-estimated plume optical properties involve greater uncertainties than the geometric properties, and show patterns consistent with smoke aging. Optical depth increases by 15-25\% in the down-plume direction, consistent with hygroscopic growth and nucleation overwhelming the effects
\end{abstract}

of particle dispersion. Both particle single-scattering albedo and top-of-atmosphere reflectance peak about halfway downplume, at values about $3 \%$ and $10 \%$ greater than at the origin, respectively. The initially oblong plumes become brighter and more circular with time, increasingly resembling smoke clouds. Wind speed does not explain a significant fraction of the variation in plume geometry. We provide a parameterization of plume shape that can help atmospheric models estimate the effects of plumes on weather, climate, and air quality. Plume age, the age of smoke furthest down-plume, is lognormally distributed with a median of $2.8 \mathrm{~h}$ (25th and 75 th percentiles at $1.3 \mathrm{~h}$ and $4.0 \mathrm{~h}$ ), different from the median ages reported in other studies. Intercomparison of our results with previous studies shows that the shape, height, optical depth, and lifetime characteristics reported for tropical biomass burning plumes on three continents are dissimilar and distinct from the same characteristics of non-tropical wildfire plumes.

\section{Introduction}

Humans burn natural tropical forests and peatland ecosystems in Southeast Asia to convert them into landscapes more suitable for agriculture (Miettinen et al., 2011). Peat and deforestation fires in Indonesia are particularly severe, and can account for $30 \%$ of global open fire emissions of $\mathrm{C}$ in dry years (Page et al., 2002; van der Werf et al., 2006, 2008). The condensed portions of fire-generated emissions often appear as visible plumes emanating and carried downwind from the burn region, sometimes merging into larger 
scale smoke clouds of indistinct origin. In regions like Indonesia, smoke plumes and clouds are frequent and extensive enough to significantly alter the energy budget by shadowing the ground and heating the atmosphere aloft (Duncan et al., 2003; Tosca et al., 2010). Moreover, our model results (Tosca et al., 2010) suggest that smoke may reduce regional SST and dry-season precipitation, causing a potential feedback that increases drought-stress and air quality problems during El Niño years.

The island of Borneo experiences thousands of fires per year. Aerosol plumes emitted by these fires are numerous especially in the peatlands during the dry season of August to October (e.g., Page et al., 2002). In El Niño years high pressure over the Western Pacific is conducive to abnormally dry conditions in Indonesia, where plumes can congeal into undifferentiated smoke clouds that degrade air quality for weeks, with particulate concentrations up to 20 times greater than normal (Davies and Unam, 1999). Such dangerous air quality episodes occur in the presence of persistent smoke clouds that form in stable meteorological conditions from an aggregation of individual smoke plumes. Characterizing the evolution of these smoke plumes improves both air quality prediction (Henderson et al., 2008) and our understanding of anthropogenic effects on changes in regional climate (Tosca et al., 2010). Here we study smoke plumes rather than smoke clouds because plumes have a discernible shape which can be characterized, and a transport direction that allows heights and wind speeds (and thus plume ages) to be more accurately estimated from MISR imagery.

The shapes and ages of continuous fixed-source plumes are well-studied due to their importance in air pollution meteorology (e.g., Seinfeld and Pandis, 1998, Chap. 17). However, the horizontal dimensions, shapes, time evolution and ages of open fire-generated plumes have not been studied as extensively. In contrast to a continuous fixed-source plume e.g., from an industrial smokestack, a fire-generated plume from open burning can have a continually varying emission intensity dependent on fuel availability, an injection height that depends on fire temperature and atmospheric stability, and a changing area of origin due to fire movement.

For our purposes smoke plumes may be divided into three broad categories of origin: tropical forests (where plumes typically arise from anthropogenic deforestation), savanna/grasslands, and temperate or boreal forests. We will not consider or discuss plumes arising from intense pyrocumulonimbus events because these are rare (e.g., Fromm and Servranckx, 2003) and are not expected to have height and shape distributions drawn from the same populations as the more commonly occurring plumes from low-intensity fires studied here. Plumes can be further differentiated by their geographic origins, fuel loads and types of source fires, and connection to meteorological circulations on multiple scales (e.g., Reid et al., 2012). In general, tropical forest fires have the greatest fuel loads, followed by boreal forest fires and savanna wildfires (van der Werf et al., 2006). Savanna wild- fires accounted for over $80 \%$ of the global burn area between 1997 and 2004, though tropical and boreal forest fires were responsible for approximately $50 \%$ of fire $\mathrm{C}$ emissions during the same period (van der Werf et al., 2006). Even among tropical biomass burning plumes, there are wide variations in characteristics owing to differences in burn type (smoldering peat vs. flaming combustion), terrain, and meteorology (van der Werf et al., 2003; Tosca et al., 2011).

A systematic understanding of the characteristics (horizontal dimensions, shapes, time evolution and ages) of open fire-generated plumes has not yet been attempted, neither in the tropics, where seasonal biomass burning dominates, nor in the extratropics, where wildfires are also important, nor of any characteristic differences between these two regimes. Plume heights have been related to plume optical properties in both the tropics and extratropics: Guan et al. (2010) found that for plumes less than 2 days old, plume height was strongly correlated with aerosol index, a measurement of the contribution of aerosols to UV scattering. Tosca et al. (2011) characterize the seasonal and interannual distribution of occurrence, height, fire radiative power, and relationship to rainfall of fire-generated smoke plumes and clouds on Borneo and Sumatra from 2001-2009. They found that $96 \%$ of these plumes reside within $500 \mathrm{~m}$ of the Atmospheric Boundary Layer (ABL), with a mean height of $709 \pm 14 \mathrm{~m}$. Plumes in Borneo and Sumatra exhibit similar distributions of height above the ABL in comparison to previous studies of smoke plumes in Alaska (Kahn et al., 2008) and in North America (Val Martin et al., 2010). While some of the variation in height is attributable to different biome types and environmental conditions (e.g. drought), the similarities in height distribution about the ABL suggest that processes governing the vertical distribution of plumes can be similar in geographically disparate regions. Aged plumes no longer associated with a clear fire source (hereinafter called smoke clouds, as per Tosca et al., 2011) can reach significantly greater heights, with Californian smoke several days old reaching $5 \mathrm{~km}$ (McKendry et al., 2011), while Siberian smoke events averaging 5.5 days old reached from 1.5 to $6 \mathrm{~km}$ (Paris et al., 2009). Additionally, smoke clouds are often located significantly higher than predicted by their aerosol indices (Guan et al., 2010), and higher than their plumes of origin (Tosca et al., 2011).

Plume length (i.e., distance down-plume from the source) has been empirically characterized and area and shape have been modeled in North America. North American smoke plumes during the 2002 and 2004-2007 fire seasons have mean length $26 \mathrm{~km}$, while smoke plumes from Central American tropical forests have mean length $15 \mathrm{~km}$ (Val Martin et al., 2010). The Indonesian plumes we describe below are approximately three times longer than the Central American plumes, and the potential roles of sampling, local meteorology, and fire characteristics in explaining this discrepancy will be discussed below. Plume extent from wildfires in British Columbia has been modeled based on 
MODIS-derived fire radiative power and estimated particle emission rates (Henderson et al., 2008). This study will present the first estimates of Borneo tropical biomass burning plume shape, length, area, and width-to-length ratio and their interrelationships.

Optical properties of plumes include optical depth and reflectance, which are determined by particle size, concentration, composition, and surface albedo. Optical depth varies widely: smoke observed at AERONET stations in the Amazon and the Brazilian cerrado in the 1990s was nearly twice as optically thick as smoke from the boreal forest in the US and Canada (Reid et al., 2005a), although this masks the large spread in properties of individual events due to local meteorology and dispersion. Reid et al. also report that AERONET stations sampling boreal forest fire smoke record slightly greater single-scattering albedos (SSAs) than stations sampling tropical forest fire smoke. Both tropical and boreal forest fire smoke are substantially brighter than savanna fire smoke measured by AERONET. Additionally, smoke from five fires in Indonesia during October 1997 had a higher albedo than that recommended by Reid et al. for tropical forest fire smoke (Gras et al., 1999). Aged smoke aerosols often have a higher SSA than fresh smoke (Reid et al., 1998; Gras et al., 1999; Abel et al., 2003), a phenomenon which Abel et al. attribute to secondary organic aerosols and to hygroscopic growth of existing aerosols). Smoke aerosol darkening after emission may occur when coatings focus more light on internally mixed black carbon (e.g., Bond et al., 2006), or when emissions mix with aerosols from other combustion sources (Reid et al., 2005a, Section 2.4). Our study re-examines the optical properties of Indonesian fires with two orders of magnitude more data than Gras et al. and analyzes the evolution of aerosol properties down-plume from the perspective of the spatially resolved plume imagery captured by MISR.

Age is an important property of fire-generated plumes because the plume extent and optical properties, and thus health and climate impacts, evolve with age until plumes merge or dissipate. Siberian smoke observed in 2008 had ages of 1 to 13 days, with a mean of 5.5 days (Paris et al., 2009). This smoke was observed hundreds of kilometers from active fires. Following the convention described in Tosca et al. (2011), we would characterize this smoke as arising from "smoke clouds" rather from than "smoke plumes," as it is not associated with a clear fire source. As expected, older smoke clouds are found further from observed fire locations (Paris et al., 2009). Using a procedure similar to ours, Val Martin et al. (2010) found that North American smoke plumes (i.e., clearly differentiated and associated with a fire source) have a median age of $2 \mathrm{~h}$. This study estimates, for the first time, the distribution of plume ages from regularly occurring open fire- generated plumes.

This study aims to characterize the horizontal and temporal evolution of regularly occurring biomass burning plumes in order to facilitate incorporation of such plumes and their effects into meso- and larger-scale atmospheric and air pollution models. Whereas previous studies have used MISR data to characterize the mean properties of smoke plumes (Nelson et al., 2008; Val Martin et al., 2010; Tosca et al., 2011), ours examines a broader variety of properties, including intraplume features. The shape characteristics most fundamental to understanding the energetic impact of a plume are its overall scale and width-to-length ratio. Using Borneo fires from 2001 to 2009, we develop an empirical probability distribution function (PDF) of the frequency occurrence of plumes a given distance down-plume and cross-plume from the fire source. We also characterize the down-plume changes in optical properties, which integrate the evolution of particle concentration, composition, and hygroscopicity.

The study is organized as follows: Sect. 2 describes the data sources, sampling techniques, and methods used to generate the database of fire plumes. Section 3 presents our results on the shape, size, directionality, down-plume evolution and age of our nine-year database of Borneo plumes and develops the PDF of the size and shape of the plume ensemble. Section 4 establishes the relationship between our results and previous studies. Section 5 summarizes our results and suggests areas for further studies.

\section{Methods}

All data analyzed in this study were obtained from measurements made by the Multi-Angle Imaging Spectro-radiometer (MISR) instrument aboard the Terra satellite. MISR uses nine cameras, each set at a different angle relative to the ground, to produce a stereo-image of the Earth's surface and atmosphere (Diner et al., 1998). As MISR crosses the equator at 10:30 a.m. local time (LT) during each orbit, Borneo is always imaged during the late morning (Nelson et al., 2009). In this manuscript, we relied on two precompiled databases of Borneo smoke plumes occurring between January 2001 and December 2009. These databases are identical to those described by Tosca et al. (2011), wherein further details may be found. For convenience and conciseness, only the most salient details of the methodology will be repeated here.

\subsection{Creation of plume database}

This study defines "plumes" as areas of smoke clearly originating from a source fire, as contrasted with "clouds," diffuse areas of smoke with no clear point of origin. Plume candidates were identified by visually inspecting all MISR scenes ( 300 by $360 \mathrm{~km}$ blocks) between 2001 and 2009 containing a MODIS-identified fire (Giglio et al., 2006a). The perimeter, origin, and down-plume direction of each smoke plume candidate were manually traced (by M. Tosca) using the MISR INteractive eXplorer (MINX) digitization procedure (Nelson et al., 2009). Plumes were only accepted for inclusion in the database if they exhibited substantial opacity, had a clearly 
defined transport direction, and were not fully obscured by water clouds. Furthermore, all plumes were visually associated with a point source, in contrast to larger "smoke clouds," masses of smoke with no discernible surface origin.

The MINX plume digitization algorithm was designed specifically for smoke plume analysis, as opposed to more widely-applicable MISR wind and aerosol height retrieval algorithms. Rather than attempting to solve for wind speed, wind direction, and height, MINX takes wind direction as a user-generated input, visually determined based on the source fire and terminus, and solves for only two variables, wind speed and height. As a result, the MINX digitization process is quite sensitive to proper determination of the transport direction. Moreover, our definition of plumes as having a clearly defined transport direction is crucial in allowing use of MINX to compute heights and wind speeds.

MINX uses MISR imagery as an input to determine height and wind speed on a $1.1 \mathrm{~km}$ scale. MINX considers seven of MISR's nine cameras, the nadir camera at $0^{\circ}$ inclination and three of the four pairs, with each pair consisting of one front-facing and one rear-facing camera. For each of the camera pairs, MINX computes the disparity in the apparent location of a particular feature on the underlying terrain, which arises from the parallax created by the different angles of the two cameras. MINX then models disparities for each camera, minimizing the difference between the modeled and observed disparity. Since the parallax caused by satellite movement cannot be distinguished from the motion of the feature due to wind, this modeling process produces a line of height/wind speed values rather than a unique solution. However, when the user specifies the wind direction, the intersection of the height/wind solution line with the plane containing all allowed wind vectors yields a unique solution. To compute this solution, MINX first assumes a wind speed of zero and loops through all possible heights to determine the zero-wind height. Then, using the zero-wind height as a starting point, MINX loops through height and wind speed combinations to find the solution that minimizes the difference between the modeled and observed disparities. Poor retrievals (e.g., those originating from MINX confusing ground imagery with atmospheric imagery) and outlying data points are eliminated, and the remaining height/wind solutions are averaged over the three camera pairs to produce an estimate of feature height and wind velocity. The MINX process only outputs heights and wind vectors: plume optical characteristics, size and shape are simply read from the MISR standard product.

388 plumes were selected to form the first plume database, with each plume containing between 7 and 2245 pixels. In this database, if part of a plume was obscured by a water cloud, the plume perimeter was drawn through the cloud following the plume's expected perimeter. A second database was created when the plumes were redrawn by a second user (D. Nelson). In this database, the plume perimeter was drawn around water clouds to reduce contamination. $18 \%$ of the initial plumes were redrawn by D. Nelson, $15 \%$ were deleted, and $2 \%$ were added, resulting in a total of 333 plumes. Tosca et al. (2011) report a total of 317 plumes in the second database, but they exclude those plumes containing very few (less than five) wind-corrected height retrievals. For this database, careful consideration was made to remove all potential water cloud contamination, during both the manual digitization phase and the post-processing screening phase, because water clouds were generally higher and brighter than smoke plumes. Since the first plume database more faithfully reproduces plume shape, it was used to study plume geometric properties. The second database was used to study plumes' optical properties and heights, which are more sensitive to cloud contamination. Between the two databases, our results have no qualitative differences, only small quantitative differences.

The MISR overpass at 10:30 a.m. LT misses the diurnal peak in fire activity (15:00-18:00 LT) in land regions of the maritime continent (Reid et al., 2012). The peak is quite pronounced (three-to-ten times more afternoon than morning fires) in Borneo, the source region for our plume database. As a consequence, the database likely overrepresents (longer) plumes formed from persistent fires burning overnight, and under-represents (shorter) plumes from fresh fires (J. Reid, personal communication, 2012). In fact, about $73 \%$ of the plumes are from peat forests (Tosca et al., 2011), which are expected to burn longer than fires in nonpeat ecozones. Moreover, $83 \%$ of the plumes are from El Nino years $(2002,2004,2006,2009)$ when low precipitation favors persistent fires. Overall, MISR's morning overpass preferentially samples plumes from persistent fires that are likely, therefore, to be longer than an unbiased sample. We will return to this point in Sect. 4.

\subsection{Optical properties and plume height}

This study reports the down-plume evolution of optical depth, single-scattering albedo (SSA), and top-ofatmosphere reflectance. Wind speed, plume coverage, and height are gridded at $1.1-\mathrm{km}$ intervals, while optical depth, top-of-atmosphere reflectance, and SSA are reported in 17.6$\mathrm{km}$ blocks. As a result, many adjacent points repeat the same optical depth, SSA, and reflectance values. MISR provides optical depth and single-scattering albedo in blue, green, red, and near-infrared bands. Here we show optical depth and SSA in the green band (wavelength $\lambda=558 \mathrm{~nm}$ ) where insolation peaks. Neither optical depth nor SSA have valid retrievals in regions of high opacity or cloud contamination (Nelson et al., 2009), resulting in a maximum reported optical depth of 2.5. According to J. Reid (personal communication, 2012), MISR underestimates AOTs by a large fraction, while MODIS overestimates them. Moreover, retrieval errors are likely to be large in regions of transition from high to low AOT (such as plume edges) where multiple scattering effects are important. We return to this point in Sect. 3.2. 
Since the MISR science team strongly cautions against detailed analysis of top-of-atmosphere reflectance data (Nelson, et al., 2009), we refer only to its general trends, which are less sensitive to absolute calibration and retrieval errors. For all three optical parameters, we also calculate relative values by dividing each optical property value by its maximum value in each plume.

In this manuscript, plume height is defined as the difference in altitudes between the top of the plume and the terrain. MINX estimates both zero-wind and wind-corrected altitudes above sea level. Wind correction is necessary because in the presence of a wind with a nonzero ground-track velocity component, a difference in plume position between two cameras can be attributed both to parallax and to wind motion, creating a potential source of error when height is estimated from the observed parallax alone (Kahn et al., 2007). As a result, wind-corrected heights are preferable to zerowind heights and are used in the analysis below. MISR also estimates the altitude of the ground terrain above sea level, which must be subtracted from the plume altitude to obtain plume height. Again, both absolute and relative (i.e., relative to the maximum height of the plume) heights are considered.

\subsection{Geometric properties and wind measurements}

In this study, we considered both actual and relative plume shape. To measure actual plume shape, we translated each plume to a fixed Cartesian coordinate system with a common origin. Since Borneo lies between $4^{\circ} \mathrm{S}$ and $6^{\circ} \mathrm{N}$ latitude, we used the Equatorial conversion factor of $111.32 \mathrm{~km} /{ }^{\circ}$ longitude or latitude to convert MISR-provided location data to $\mathrm{km}$. To describe relative plume shape, we rotated each plume so that its area-weighted centroid lay on the $x$-axis and scaled each plume to have unit length, creating normalized plumes with a varying width, the "cross-plume width." Using relative coordinates, we present plume fraction, the proportion of all plumes that exist at a given point. From this graph, we define the "mean plume" as all points with a plume fraction greater than 0.05 .

MINX retrieves wind velocity in the "across-track" and "along-track" components, corresponding to the spacecraft's direction of motion. In order to derive both cardinal direction wind components and down-plume and cross-plume wind components, we perform two transformations of wind speed. The Terra satellite orbital inclination is $98.2^{\circ}$, and its measurements are archived on an orthogonal grid in the across-track and along-track directions. We rotate each wind vector by this estimated direction of motion to obtain zonal and meridional winds. We also compute the angle between the plume centroid and north, and rotate the wind velocity by this angle to obtain down-plume and cross-plume wind components. All individual wind vectors are averaged to produce a mean wind vector for each plume.

We consider three definitions of cross-plume width in relating down-plume wind speed to cross-plume width. In the first definition, cross-plume width is the distance between the maximum and minimum relative $y$ coordinates (the $y$ coordinate normalized by the plume length). This definition is used except where indicated for all other plume width estimates. The second definition compares relative $y$ coordinates only to other $y$ coordinates with similar $x$ values. First, we calculate the maximum distance $d$ between consecutive $x$ values, and divide the plume into $1 / d$ regions. For each region, considering only points within that region, we compute the difference between the maximum and minimum relative $y$ coordinates. Under the second definition, cross-plume width is equal to the largest of these differences. According to the third definition, cross-plume width is equal to the average difference.

To parameterize relative plume shape, we first convert measured plume fraction into a plume density PDF by dividing each plume fraction value by the sum of all plume fraction values. We then fit this PDF to the ovoid shape parameterization $A(x-0.5)^{2}-B y^{2}+C x y^{2}+D$, by selecting the $A, B, C$, and $D$ combination which minimizes root mean square error (RMSE),

RMSE $=\sqrt{\frac{1}{N} \sum_{i=1}^{N}\left(x_{i}-y_{i}\right)^{2}}$

where $x_{i}$ is the predicted plume density and $y_{i}$ is the actual plume density. We ignore the origin when calculating RMSE, because by definition it has a plume fraction value of 1 , far greater than any other value.

\subsection{Plume age}

Plume age is defined as the age of smoke at the most distant point from the plume origin. Plume age $(A)$ is approximated by the ratio of plume length $(L)$ to average down-plume wind speed $\left(\mathrm{WS}_{X}\right)$

$A=\frac{L}{\mathrm{WS}_{X}}$

We also estimate the standard deviation of plume age $\left(\sigma_{\mathrm{A}}\right)$ for each plume. First, we estimate the standard deviation of down-plume wind speed ( $\left.\sigma_{\mathrm{WS}}\right)$ for a single plume:

$\sigma_{\mathrm{WS}}=\sqrt{\sigma_{X}^{2}+E_{R}^{2}}$

where $\sigma_{X}^{2}$ is the variance of all down-plume wind speed measurements, and $E_{\mathrm{R}}$ is random error. The error associated with the MINX wind speed estimates is not well established. The estimated error of the standard MISR wind retrieval is $2.9 \mathrm{~m} \mathrm{~s}^{-1}$ (Davies et al., 2007), and the MINX algorithm is considered more accurate than the MISR retrievals (Nelson et al., 2009). In this paper, we conservatively estimate MINX wind speed error at $2.9 \mathrm{~m} \mathrm{~s}^{-1}$ for each wind retrieval, thus

$E_{\mathrm{R}}=\frac{2.9}{\sqrt{n}}$ 
Next, we compute $\sigma_{\mathrm{A}}$ from $\sigma_{\mathrm{WS}}$ :

$$
A=\frac{L}{\mathrm{WS}_{X}}=\left(\frac{L}{\mathrm{WS}_{X}^{2}}\right) \times \mathrm{WS}_{X}
$$

Since

$\sigma_{B X}=B \sigma_{X}$

$\sigma_{\mathrm{A}}=\left(\frac{L}{\mathrm{WS}_{X}^{2}}\right) \times \sigma_{\mathrm{WS}}$

While 359 plumes have $\sigma_{\mathrm{A}}<24 \mathrm{~h}$, five plumes have $\sigma_{\mathrm{A}}>$ $1000 \mathrm{~h}$. These high standard deviations result mainly from long, low wind-speed plumes with few valid wind measurements. Many of these plumes have exceptionally high plume ages, likely indicating changes in wind speed or poor plume digitizing. As a result, plumes with a standard deviation greater than $24 \mathrm{~h}$ are excluded from the analysis.

Error bars based on the standard deviations of each hourly plume age bin are also reported as

$$
E=\frac{1}{N} \sqrt{\sum_{i=1}^{N} \sigma_{\mathrm{A}}^{2}}
$$

where $N$ is the number of plumes in the bin.

\section{Results}

\subsection{Geometric properties}

An assortment of twelve plumes from our database generally conform to an ovoid shape with a much greater length than width (Fig. 1). Plumes were digitized around water clouds even if those clouds lay above the plume, resulting in the gaps observed in Fig. 1a (i.e., plume 4 from year 2002), g and i. As mentioned above, relative optical depth varies in discrete steps rather than continuously, since optical depth is reported on a $17.6-\mathrm{km}$ grid while plume location is reported on a 1.1-km grid. Some plumes (Fig. 1c, d, h, k) contain valid optical depth retrievals at all points. Such plumes cannot contain points with optical depth $>2.5$ and are also unlikely to be contaminated by water clouds. Other plumes lack valid optical depth retrievals at some points (e.g., Fig. 1f, g) or even all points (Fig. 1a, 1), where optical depths may have exceeded 2.5. Relative optical depth does not follow any consistent trend within each plume, as maxima are found near the origin, in the middle of the plume, and at the plume's end. The mean, standard deviation, and median characteristics for all plumes are, respectively: length 41,27 , and $35 \mathrm{~km}$, optical depth $0.74,0.49$, and 0.65 , and width-to-length ratio $0.27,0.15$ and 0.24 , with a sample size of 388 plumes for length and width-to-length ratio and 333 plumes for optical depth. While we present the standard deviations of length

\section{Optical Depth of 12 Borneo Smoke Plumes}

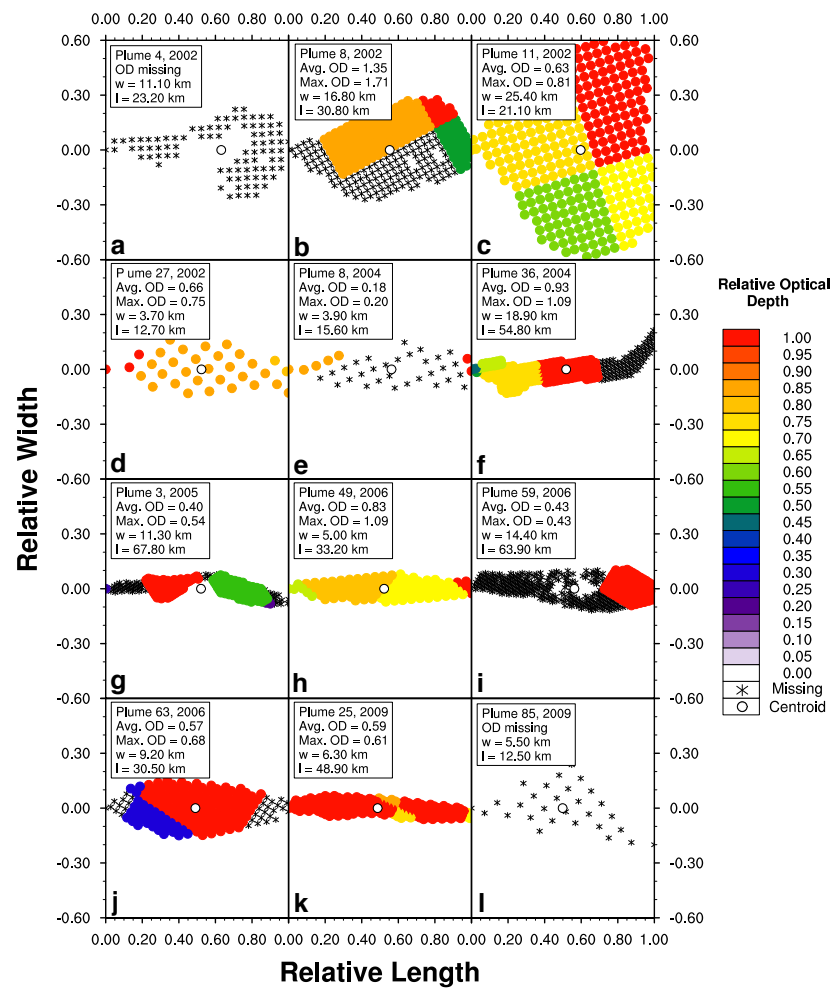

Fig. 1. Shape, area-weighted centroid, and relative optical depth of 12 representative plumes arranged chronologically. Information box in upper left indicates year and order the plume was imaged (e.g., (k) shows the 25th plume imaged in 2009), average plume optical depth, maximum optical depth, actual width, and actual length.

and length-to-width ratio to quantify the spread observed in the data, note that these quantities are described by a lognormal rather than by a Gaussian distribution.

Smoke plumes and wind vectors are oriented in nearly the same direction (Fig. 2). Wind speeds average $3.5 \pm 2.5 \mathrm{~m} \mathrm{~s}^{-1}$ directed $55.5^{\circ} \mathrm{N}$ of $\mathrm{W}$ (Fig. 2a), while plume lengths average $41.4 \mathrm{~km}$, with centroids directed $52.2^{\circ} \mathrm{N}$ of W (Fig. 2b). $87 \%$ of all wind vectors lie between due west and due north, while $88 \%$ of all centroids lie in the same region. The 25th and 75th percentiles for mean wind speeds are 2.1 and $5.5 \mathrm{~m} \mathrm{~s}^{-1}$, respectively, while the 25 th and 75 th percentiles for plume length are 23.6 and $50.4 \mathrm{~km}$, respectively. Prevailing southeasterly winds and southerly sea breezes are primarily responsible for the observed orientation of smoke plumes. Most Borneo smoke plumes are located directly north of the Java Sea in Central Kalimantan Province (Tosca et al., 2011). Borneo smoke plumes are exclusively imaged in the morning at the 10:30 a.m. local overpass time, when southerly sea breezes blow from the Java Sea, consistent with the southerly orientation of the mean wind vectors.

Plumes were primarily observed in Central Kalimantan Province, with $73 \%$ of plumes occurring in peat regions 
Plume Fraction and Endpoint

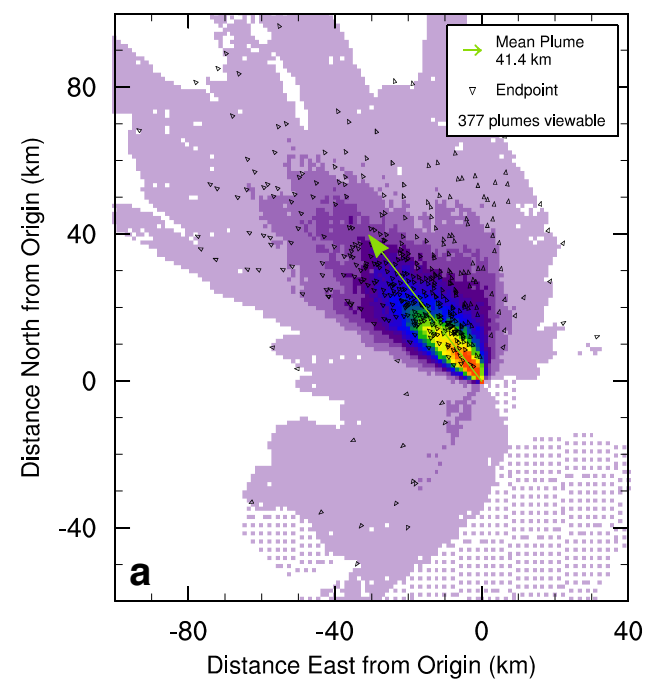

Plume Wind Velocity

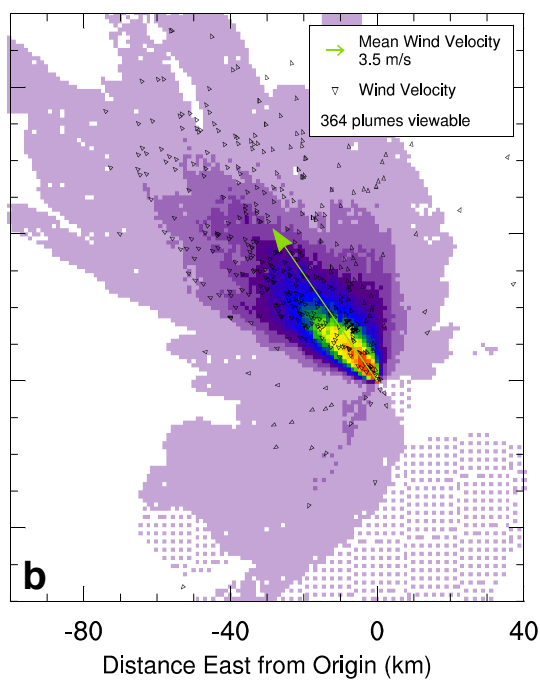

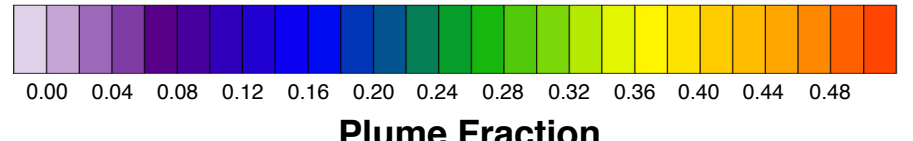

Plume Fraction

Fig. 2. Plume fraction (colors) overlaid with endpoints and wind velocities (triangles). (a) Triangles represent the most distant point of each plume transformed to lie on the origin-centroid axis. Green arrow shows mean plume length $(41.4 \mathrm{~km})$. (b) Triangles represent the mean wind vector for each plume scaled so that the overall mean wind vector $\left(3.5 \mathrm{~m} \mathrm{~s}^{-1}\right)$, represented by the green arrow) is equal in length to the mean plume length.

(Tosca et al., 2011, Fig. 1). Additionally, Borneo plumes were primarily observed in the dry season between August and OCtober (Tosca et al., 2011, Fig. 2), and $83 \%$ of the plumes in the database occurred in the El Niño years of 2002, 2004, 2006, and 2009.

Plume length is distributed lognormally, with mean $41.1 \mathrm{~km}$ and median $35.2 \mathrm{~km}$ (Fig. 3a). Normalized plume width is distributed in a similar lognormal fashion, with mean 0.268 , standard deviation 0.147 , median 0.236 , and 25 th and 75th percentiles at 0.18 and 0.30 (Fig. 3b). Plume area also follows a lognormal distribution, with mean $261 \mathrm{~km}^{2}$, median $169 \mathrm{~km}^{2}$, standard deviation $300 \mathrm{~km}^{2}$, and $25 \mathrm{th}$ and 75 th percentiles at $99 \mathrm{~km}^{2}$ and $304 \mathrm{~km}^{2}$ (Fig. $4 \mathrm{a}$ ). $90 \%$ of all plumes are shorter than $74 \mathrm{~km}$, narrower than 0.41 times plume length, and cover less than $557 \mathrm{~km}^{2}$. Plume area and plume length follow a power-law relationship

$y=1.05 x^{1.43}$

with an $r^{2}$ of 0.83 (Fig. 4b). This relationship can be approximated linearly

$y=9.71 x-141$

for lengths between 15 and $140 \mathrm{~km}$. However, the linear relation is unphysical (i.e., negative) for lengths less than $15 \mathrm{~km}$, and deviates significantly from the exponential fit beyond $140 \mathrm{~km}$ where our database has only three plumes (with lengths 149, 188, and $225 \mathrm{~km}$, not shown in Fig. 4b). The exponential relationship behaves physically for all plume lengths and better captures the increase in plume width with plume length.

Combining all normalized, rotated plumes together into a composite graph of plume fraction produces an ovoid shape (Fig. 5, a nondimensionalized version of Fig. 9 of Tosca et al., 2011). The mean normalized plume, defined as all points with a plume fraction value greater than 0.05 , conforms to an ovoid shape with width-to-length ratio 0.19 .

\subsection{Optical properties and height}

Plume optical characteristics and heights (Figs. 6 and 7) are sensitive to cloud contamination, so we characterize them using the database drawn from plumes identified with more conservative cloud-screening criteria, as described in Sect. 2.1. Aerosol optical depth in Borneo smoke plumes gradually increases in the down-plume direction (Fig. 6b). On average, plume mean optical depth is 0.74 , with standard deviation 0.49 and the 25 th and 75 th percentiles at 0.32 and 1.03, respectively. Relative optical depth (i.e., ratio of optical depth to maximum optical depth) shows a more marked change, increasing from 0.6 near the origin to 0.8 at the plume's end (Fig. 6d). Recall that optical depths greater than 2.5 are not retrieved, so despite the low reported mean, the 

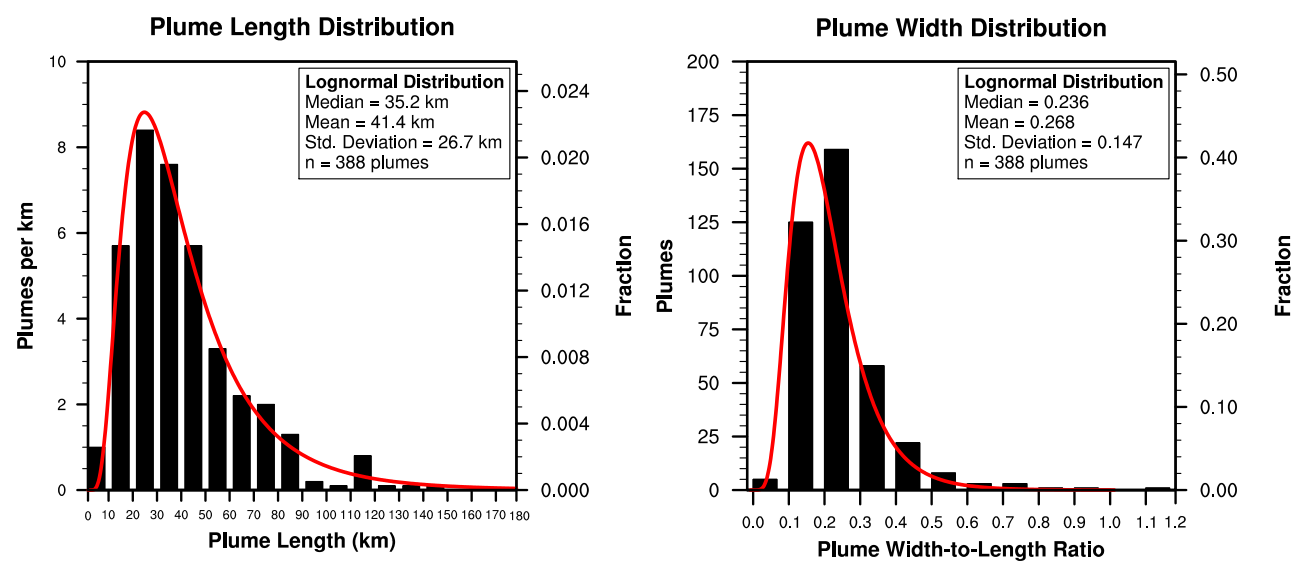

Fig. 3. Histogram of (a) length and (b) width-to-length ratio with best-fit lognormal distributions overlaid (red curves). Both plots omit 2 plumes included in the analysis.
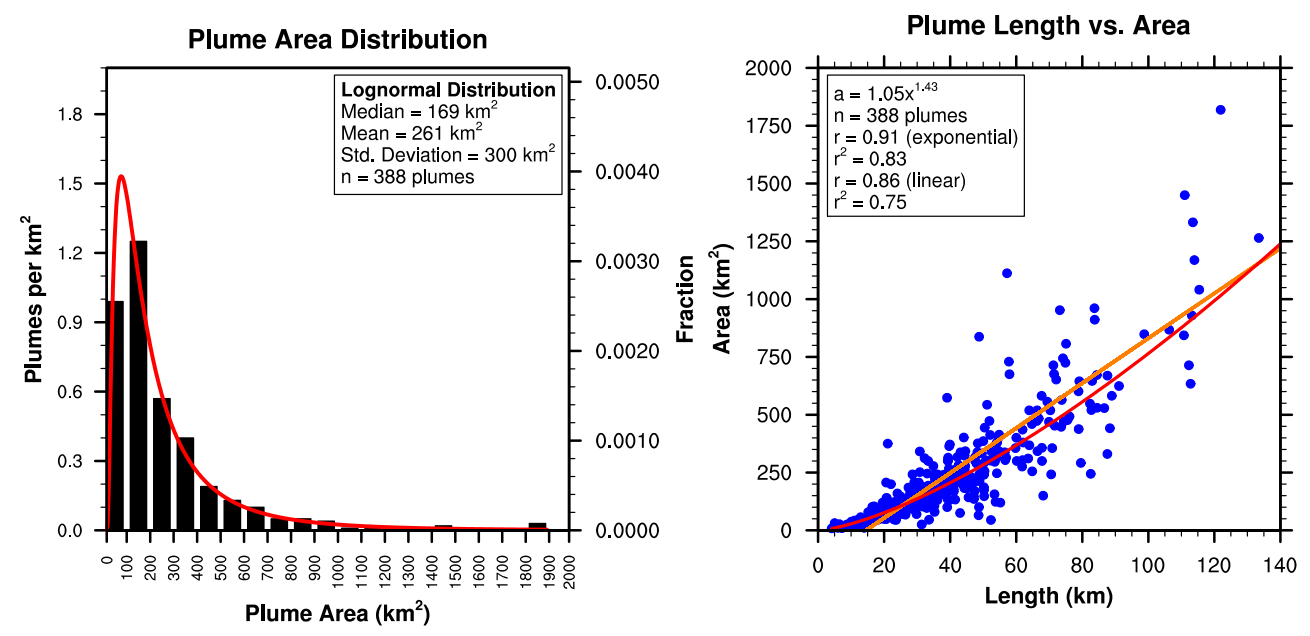

Fig. 4. Histogram of (a) plume area with best-fit lognormal distribution overlaid (red curve), and (b) exponential Eq. (9) and linear Eq. (10) relationship between length and area. Panel (a) omits 1 plume $\left(\right.$ area $=2716 \mathrm{~km}^{2}$ ) included in the analysis, and panel $(\mathbf{b})$ omits 3 plumes (lengths 149,188 , and $225 \mathrm{~km}$ ) included in the analysis.

head of the plume may actually have an equal or greater fraction of high (and thus not-retrieved) values as the rest of the plume.

The halos of thick, bright, reflective points about the plume centers in Fig. 6a, e, i result from a small fraction of the plumes, as shown by restricting the image to the mean plume, defined as all points with a plume fraction greater than 0.05 (Fig. 6b, f, j). It is possible that these thick, bright plume halos contain contamination from liquid water clouds, which tend to be optically thicker and more reflective and contain brighter particles than smoke plumes. However, enforcing stricter cloud screening criteria does not result in optically thinner or darker halos. Cloud contamination bias also fails to explain the relative optical depth halo (Fig. 6c), which consists of values lower than those found in the mean plume, indicating that among the plumes constituting the halo, optical depth decreases as distance from the mean plume in- creases. Insofar as the halos mark the edges of plumes, they are located in regions of transition from relatively high to low optical depth. In such regions the effects of multiple scattering on retrievals is more pronounced (J. Reid, personal communication, 2012), and likely to contaminate the retrieved optical properties. If the halos are real physical phenomena rather than observation errors, we think it likely that they result from aged smoke with higher single-scattering albedo and lower optical depth, which disperses uniformly, resulting in more circular plumes with a higher width-to-length ratio. Plumes with a width-to-length ratio greater than 0.5 have a median age of $4.3 \mathrm{~h}$, compared to the overall median age of $2.8 \mathrm{~h}$. The associated fires may also be older than average, resulting in especially aged smoke in the plume periphery.

Single-scattering albedo (SSA), both relative and absolute, tends to start high at the head of the plume, dip near $x=0.2$, increase near $x=0.6$, then decrease again near the 


\section{Plume Shape}

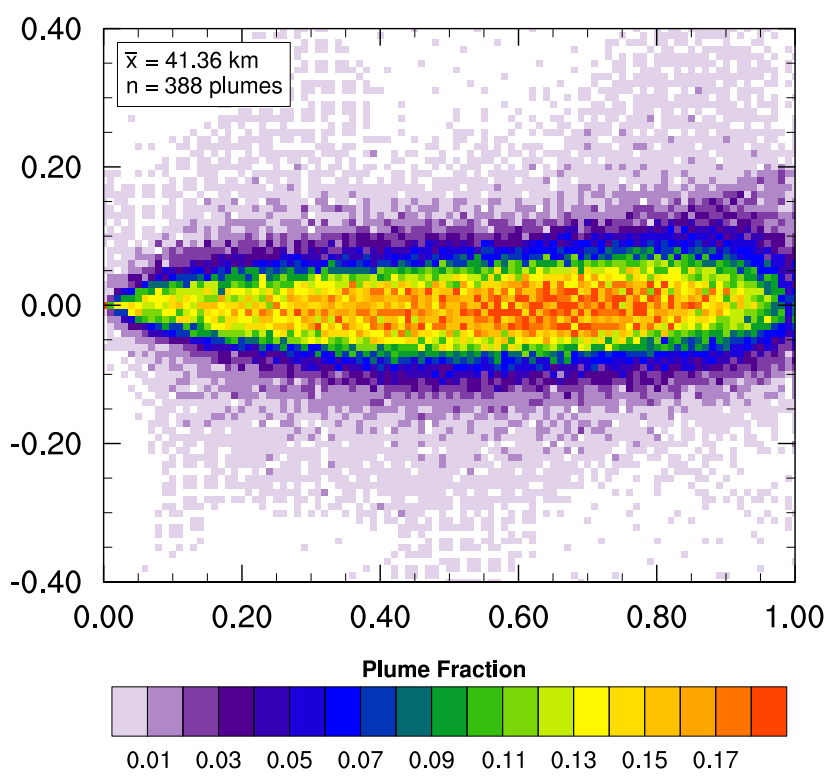

Fig. 5. Plume fraction of the composite plume, plotted in relative coordinates. Values indicate fraction of contributing $(N=388)$ plumes that are present at a point.

plume end (Fig. 6f, h). Within the mean plume, the highest SSAs are found near $x=0.6$, while the lowest are found at approximately 0.9 and 0.3 . Plume mean SSA is 0.98 with standard deviation 0.03 and plume median SSA is 0.99.

Top-of-atmosphere reflectance behaves similarly to singlescattering albedo (Fig. 6j, 1). Both peak in the center and have their lowest values at the origin and end. Top-of-atmosphere reflectance is expected to mimic particle reflectance, all else being equal.

On average, both absolute and relative plume height increase toward the origin, decline towards the center, and increase again at the end of the plume (Fig. 7b, c). Across all plumes, height averages $708 \mathrm{~m}$ with standard deviation $249 \mathrm{~m}$. The 25 th and 75 th percentiles of plume mean height are $512 \mathrm{~m}$ and $836 \mathrm{~m}$, respectively.

\subsection{Shape parameterization}

Wind speed is a poor predictor of plume shape variation. We performed several regressions of wind speed components against various measurements of plume shape, such as relative and actual plume width and actual plume length. The most significant result is the relationship between downplume wind speed and relative plume width, which we defined in three different ways (Fig. 8a-c). In all three cases, the relationships are statistically significant at the $p=0.05$ level. Increasing down-plume wind speed is correlated with a decrease in relative plume width, probably because strong down-plume winds stretch the plume in the down-plume di-
Table 1. Summary of different parameterizations and their RMSEs.

\begin{tabular}{ll}
\hline Parameterization & RMSE \\
\hline$A(x-0.5)^{2}+B y^{2}+C$ & $8.87 \times 10^{-5}$ \\
$A(x-0.5)^{2}+B y^{2}+C x+D$ & $7.99 \times 10^{-5}$ \\
$A(x-0.5)^{2}+B y^{2}+C x^{3}+D$ & $8.00 \times 10^{-5}$ \\
$A(x-0.5)^{2}+B y^{2}+C x^{4}+D$ & $8.09 \times 10^{-5}$ \\
$A(x-0.5)^{2}+B y^{2}+C x^{5}+D$ & $8.18 \times 10^{-5}$ \\
$A(x-0.5)^{2}+B y^{2}+C x y+D$ & $8.88 \times 10^{-5}$ \\
$A(x-0.5)^{2}+B y^{2}+C x y^{2}+D$ & $7.73 \times 10^{-5}$ \\
$A(x-0.5)^{2}+B y^{2}+C x y^{3}+D$ & $8.83 \times 10^{-5}$ \\
$A(x-0.5)^{2}+B y^{2}+C x y^{4}+D$ & $8.85 \times 10^{-5}$ \\
\hline
\end{tabular}

rection while leaving cross-plume width unaffected. The more complex definitions of plume width slightly increase the coefficient of determination $\left(r^{2}\right)$. However, in all cases, $r^{2}$ is so low that the relationships are not particularly meaningful.

We now describe plume density as a function of location relative to a fire origin for applications in weather and climate modelling. Plume density (Fig. 5) may be parameterized as an ovoid shape (Fig. 9a):

$$
P=-0.00161(x-0.5)^{2}-0.09676 y^{2}+0.07257 x y^{2}+0.00081
$$

where $x$ is relative plume length and $y$ is relative plume width. In comparison to other algebraic formulae with up to four terms (Table 1), this parameterization produces the least RMSE $\left(7.73 \times 10^{-5}\right)$. It overestimates plume density most significantly near the origin, and also for relative plume width values of $\pm 0.05-0.10$ (Fig. 9b). The ovoid shape underestimates plume density most significantly where plume width is approximately 0 and plume length ranges from 0.6 to 0.9 .

\subsection{Plume age}

Plume age can be described by a lognormal distribution, since the natural logarithm of plume age follows a roughly normal distribution with mean $0.99 \mathrm{~h}$ and standard deviation $0.83 \mathrm{~h}$ (Fig. 10a, b). The median plume age is $2.8 \mathrm{~h}$, with an associated standard deviation $3.0 \mathrm{~h}$. The standard error about the mean plume age is $0.3 \mathrm{~h}$, as calculated from the standard deviation associated with each plume age estimate, whose computation is described in Sect. 2.4. The 25th and 75th percentiles for plume age are $1.3 \mathrm{~h}$ and $4.0 \mathrm{~h}$, respectively. 359 plumes are considered in our study of plume age; the other 29 plumes either do not have valid ages or were eliminated from the study due to an exceptionally large standard error.

This estimate of plume age does not indicate that most plumes form around 07:30 a.m. LT, three hours before Terra passes over Borneo. It indicates that, on average, the smoke observed at the most distant portion of the plume is emitted three hours before the plume is imaged. The plume terminus is defined somewhat arbitrarily by the user digitizing the 

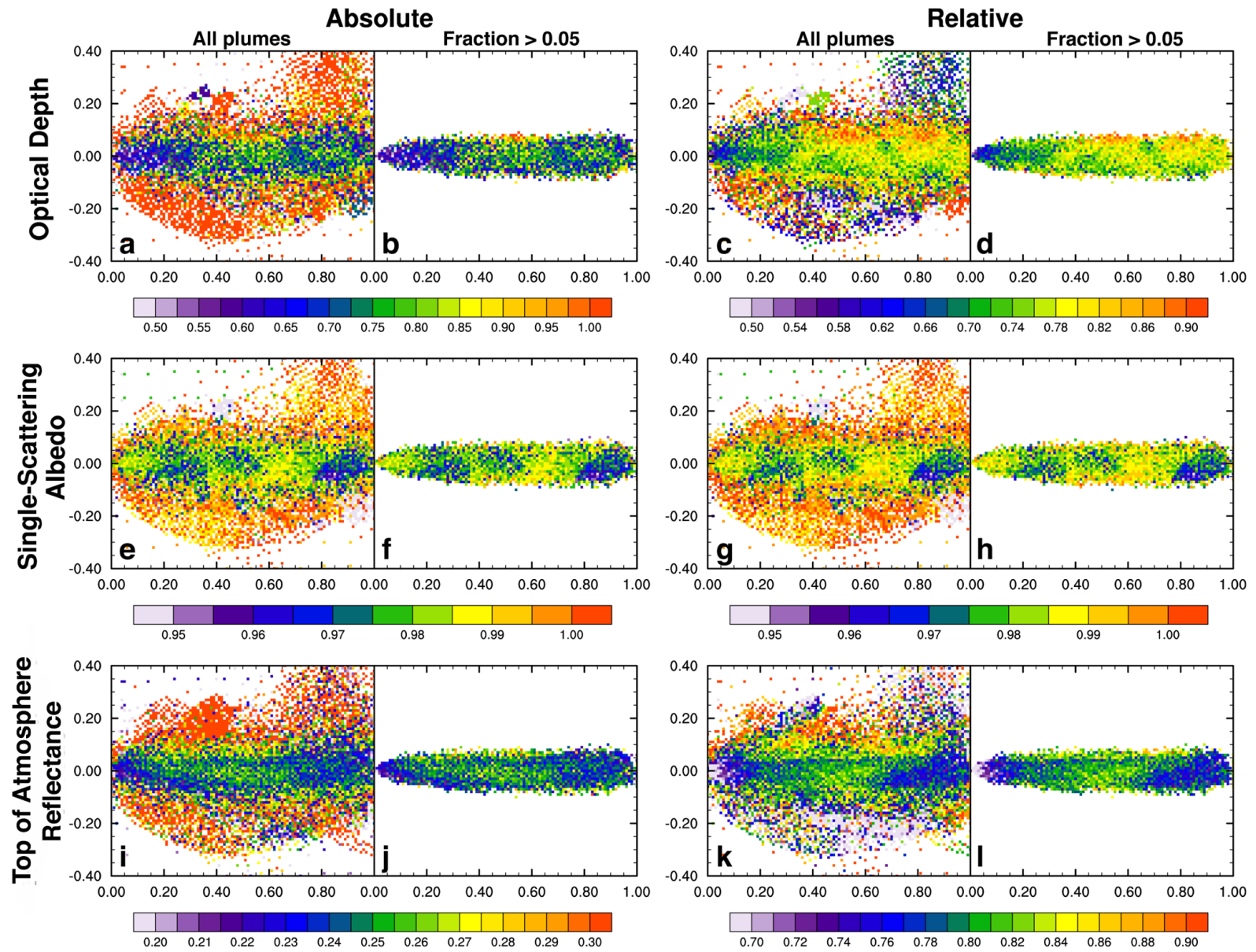

Fig. 6. Absolute and relative optical properties of all plumes and of the mean plume (fraction >0.05). (a, b) Absolute optical depth. (c, d) Relative optical depth. (e, f) Absolute single-scattering albedo. (g, h) Relative single-scattering albedo. (i,j) Absolute top-of-atmosphere reflectance. (k, l) Relative top-of-atmosphere reflectance. Within each pair of graphs, values are identical; graphs on the left show all points while graphs on the right show only the mean plume. Colors represent the average of the given optical property at that point.

\section{Plume Height}
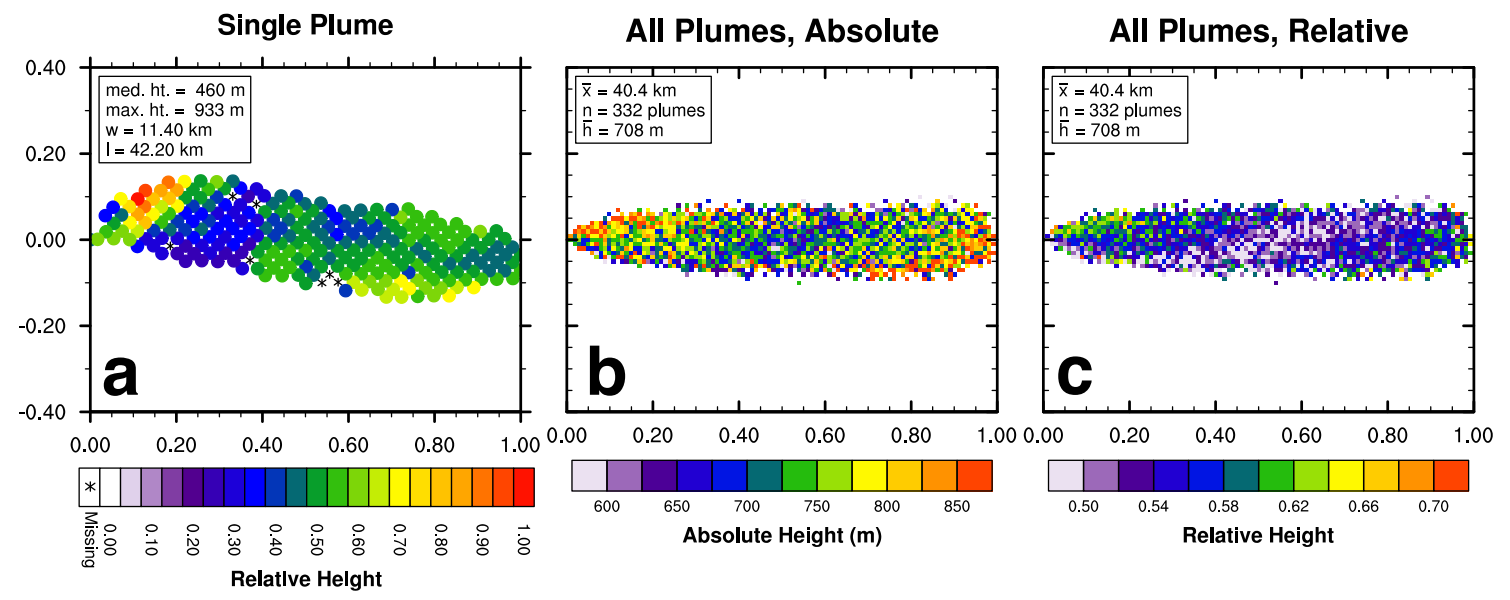

Fig. 7. (a) Relative (to maximum) plume height for the first plume from 2001, a representative plume in terms of height trends. (b) Absolute and (c) relative plume height for the mean plume (fraction $>0.05$ ), constructed as in Fig. 6b, d. 
Wind Speed (down-plume) and Plume Width
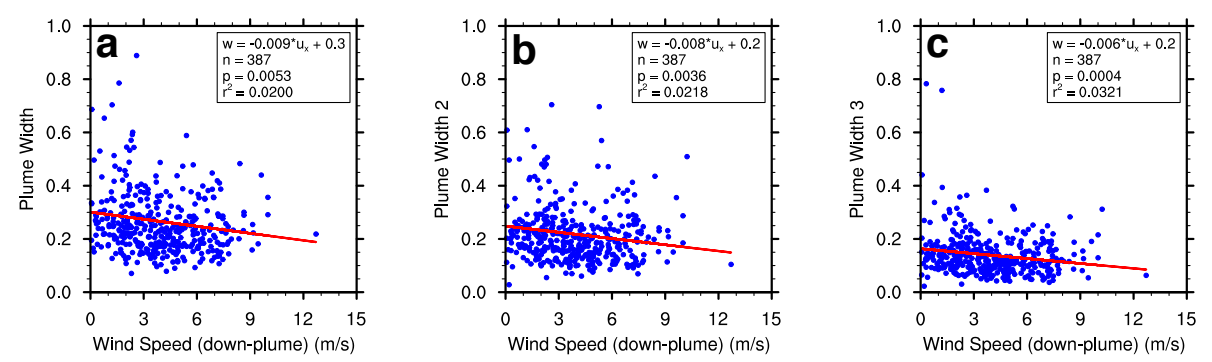

Fig. 8. Linear regression of cross-plume width $w$ and down-plume wind speed $u_{x}\left(\mathrm{~m} \mathrm{~s}^{-1}\right)$ using three definitions of wind speed defined in Sect. 2.3.

Plume Density PDF (Prescribed)

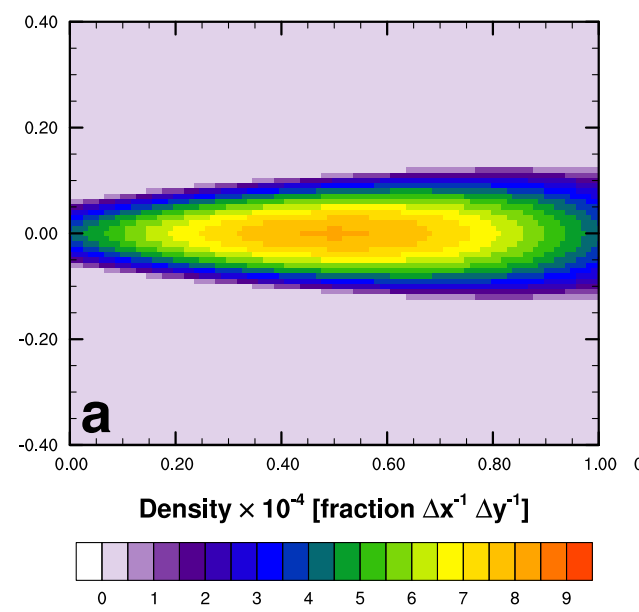

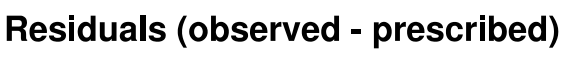

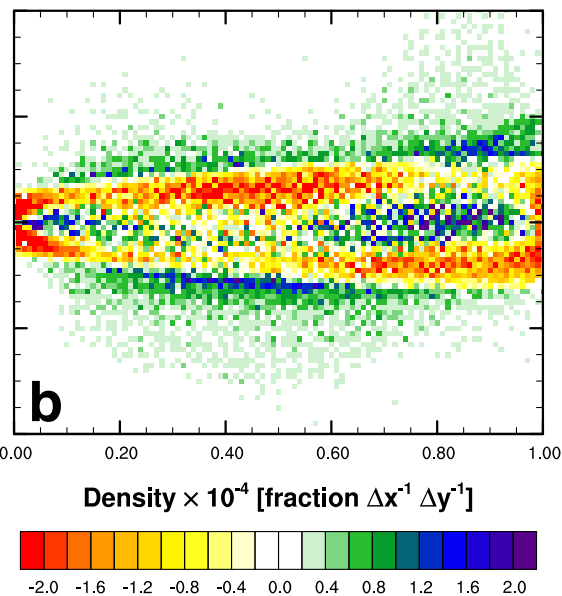

Fig. 9. (a) Best-fit parameterization of plume density. (b) Residuals computed as observed minus parameterized Eq. (11). Values are plotted in units of plume density, fraction per nondimensional unit of along-plume length and cross-plume width. Plume density, unlike plume fraction (Fig. 5), is normalized to sum to unity over the domain.

plume; thus, smoke from the plume may have traveled further than the terminus, dispersing to the point that it is hard to detect. Therefore, the plumes probably originate more than three hours before they are imaged by MISR. $99 \%$ of all plumes are less than $15 \mathrm{~h}$ old, indicating that within $15 \mathrm{~h}$, smoke from a fire generally disperses to the point that it can no longer be considered part of the plume.

\section{Discussion}

We examined 388 smoke plumes from Borneo imaged by the MISR instrument between 2001 and 2009. Using this database, we characterized shape, orientation, length, width, area, height and age of Borneo smoke plumes. We used a second database of 333 smoke plumes, redrawn to minimize water cloud contamination, to characterize optical properties, which are more sensitive to cloud contamination. The creation of both databases and the dynamics of smoke plumes associated with peat and deforestation fires in Indonesia are described in Tosca et al. (2011). In addition to our new findings on shape, down-plume evolution and age distribution, we are interested in the extent to which the shapes, heights, and brightnesses of Borneo plumes are similar to and different from those of previously studied plumes.

In 2002 and 2004-2007, tropical biomass burning plumes from Central America were found to have a mean plume length of $15 \mathrm{~km}$, with standard deviation $11 \mathrm{~km}$ (Val Martin et al., 2010). Our mean length of $41 \mathrm{~km}$ for Borneo smoke plumes, with standard deviation $27 \mathrm{~km}$, differs from Val Martin et al.'s result at the $99 \%$ significance level; the mean Central American plume length lies at the 9th percentile of Borneo plume lengths. This discrepancy most likely results from a combination of sampling bias and physical effects. While Val Martin et al.'s plume identification procedure is nearly identical to ours (they perform additional height-retrieval screening, but this discrepancy is quite minor), the sampling bias effects of the late morning overpass time may be more pronounced in Borneo. Though Central American plumes are only imaged $40 \mathrm{~min}$ later than Borneo plumes, 


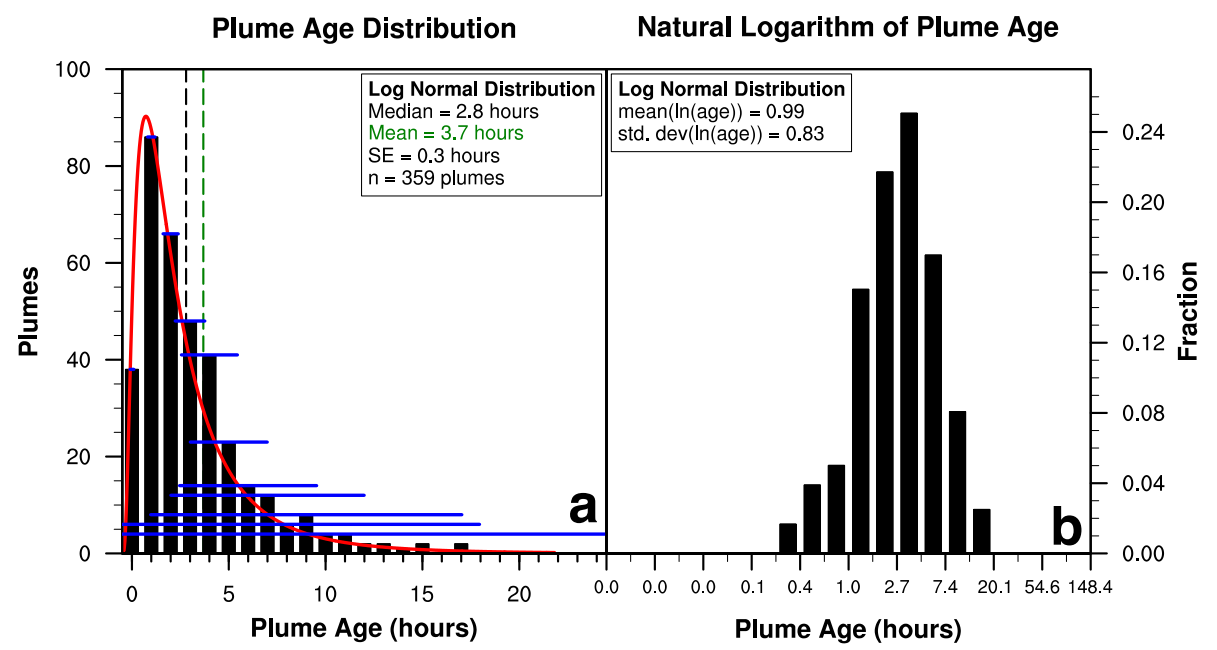

Fig. 10. (a) Histogram of plume age, with a lognormal plume age PDF superimposed. Error bars extend along the $x$-axis (plume age) rather than along the $y$-axis (plume count). (b) Histogram of the natural logarithm of (a).

at 11:10 a.m. LT, the effects of this temporal bias are much stronger in Borneo than in Central America. Since morning fires are three-to-ten times less frequent than afternoon fires (Reid et al., 2012), we expect that our database should mainly contain large peat fires burning overnight, which we would expect to produce much longer plumes. Indeed, $83 \%$ of the fires in our database are from the El Niño years of 2002, 2004, 2006 and 2009, when peatland burning dominated (e.g., Page et al., 2002; Field et al., 2009). Also, $73 \%$ of the fires were located in peat, heath forest, or freshwater swamp regions (Tosca et al., 2011, Fig. 1). In contrast, the Central American fires studied by Val Martin et al. did not arise from peatlands, nor do they exhibit as much interannual variability as Borneo fires (Val Martin et al., 2010). As a result, the late morning overpass time may cause a stronger length bias in Borneo than in Central America, contributing to the observed length discrepancy.

Other physical processes may also contribute to the observed length discrepancy. Yearly median fire radiative power (FRP) for Central American fires ranged from 50$90 \mathrm{MW}$, while Borneo fires have a median FRP of $85 \mathrm{MW}$, suggesting that differences in median fire intensity are insufficient to explain the factor of three length discrepancy. Dry season precipitation is similar $\left(2-3 \mathrm{~mm} \mathrm{day}^{-1}\right)$ in Central America (Liebmann et al., 2008) and Borneo (Tosca et al., $2010,2011)$ so it is unlikely that washout processes explain the disparity in plume lengths or lifetimes. Also, seasonal climatological surface wind speeds in Central America exceed those in Borneo. Unless unresolved, strong local diurnal circulations (e.g., sea or valley-breezes) carry most fire plumes; therefore, it is unlikely that transport processes explain the disparity in plume lengths.

The disparity in plume lengths appears to be real because it is consistent with our finding, presented below, that median North American plume age is $30 \%$ less than median Borneo plume age. Overflight time, fire intensity, washout processes and wind speed do not appear to contribute to this length disparity. One possible explanation is fuel loads. From 1997-2004, equatorial Asian fire fuel load per unit area was three times greater than Central American fuel load, and carbon emission per square meter was nearly four times greater in Equatorial Asia than in Central America (van der Werf et al. 2006, Table 4). As discussed above, sampling bias may provide a mechanism for this connection, as Borneo plumes more so than Central American plumes tend to be selectively sampled form longer, more severe peat fires that burn overnight, due to the more pronounced diurnal peak in Borneo fires.

Another explanation for the plume length disparity is the longer fire persistence in Indonesia relative to Central America. Slash-and-burn conversion of tropical peat forest to agricultural land in Indonesia is commonplace. Many fires there are re-set in order to clear lowland forests and convert them to cultivable plantations. One signature of this practice is the elevated (relative to Central America) fire persistence in Indonesia as determined from the number of days in a month when fires were present in the same 1-km MODIS fire pixel (Giglio et al., 2006b). Of course the higher fuel-loads in Indonesia probably contribute to the increased fire persistence observed there. Overall, we can attribute the discrepancy in plume length between our results and Val Martin et al.'s to a combination of longer fire persistence in Indonesia, greater fuel loads in Borneo, and flight time sampling bias, exacerbated by the strong diurnal and interannual cycles of fire emissions on Borneo.

We expected that smoke plumes would exhibit declining optical depth in the down-plume direction due to plume dispersion, but instead MISR reports a gradual increase in both relative and absolute optical depth (Fig. 6b, d). These results are qualitatively unchanged if we consider only those plumes 
with valid optical depth retrievals at all pixels. Therefore, it is likely that physical and chemical processes compensate for and even overwhelm the effects of plume dispersion on the optical thickness of the smoke as it evolves down-plume. Note that while previously published measurements describe the temporal evolution of optical properties, MISR only observes plumes at a specific instant in time, and so we must infer the ages of smoke particles based on their downplume location.

Since optical depth is the product of the individual particle mass extinction efficiency and the columnar mass of emitted particles (e.g., Reid et al., 2005a), an optical depth increase results from an increase in either or both the mass extinction efficiency and the mass-path of emitted aerosols. Hobbs et al. (2003) find that aerosol concentration in smoke from a savanna fire decreases for the first $\sim 5$ min after emission, probably due to coagulation. After this, aerosol concentration increases down-plume, probably resulting from gas-toparticle conversion of organics, which increases the downplume mass-path and provides a mechanism for increasing down-plume optical depth. Mass extinction efficiency may also increase down-plume due to hygroscopic growth and aging, i.e., coatings and condensations of organic and inorganic species (e.g., sulfates). Without in situ knowledge of the composition of emissions, it is impossible to state with certainty the roles of hygroscopic growth and aging. In general, organic aerosols are more hygroscopic than elemental carbon aerosols, and serve as condensation sites for water vapor that increases the size, reflectivity, and mass extinction efficiency of the aerosol as it flows and ages down-plume (Reid et al., 2005a). Our results are consistent with nucleation and hygroscopic growth processes increasing down-plume optical depth and mitigating the reduction in optical depth due to dispersal. The primarily peatland smoke plumes of Borneo, however, may be exceptional in this regard. Previously measured Indonesian smoke plumes (Gras et al., 1999) have a hygroscopic growth factor significantly higher than that of plumes in the African savanna, Brazilian cerrado, Amazon Basin, Mexican grasslands, and Australian brush (Reid et al., 2005a). This could be due to the higher relative humidity in the maritime continent of Indonesia, as the down-plume light extinction and thus optical depth of aged smoke may increase faster in maritime climates than elsewhere. Additionally, smoldering fires such as the peat fires responsible for many Borneo smoke plumes emit a greater percentage of organic carbon than flaming fires (Reid et al., 2005b), resulting in increased hygroscopicity, mass extinction efficiency and optical depth for Borneo smoke.

At least one study finds significantly greater optical depth in fresh than in aged smoke (Liousse et al., 1995), in contrast to our findings (Fig. 6b, d). Liousse et al. sampled smoke several days old from savanna-burning fires in the Ivory Coast, whereas in our study, aerosols furthest from the origin average only $3-4 \mathrm{~h}$ old, as estimated from the plume length and down-plume wind speed. At the finer time scale of our study, optical thickening due to hygroscopicity and nucleation (Hobbs et al., 2003; Reid et al., 2005a) can dominate the effects of plume dispersion. Moreover, some of the differences between our findings and those of Liousse et al. may be explained by the systematic differences in smoke properties between smoke emitted by smoldering peat fires and flaming grassland fires.

Biomass burning plumes in Borneo appear to contain smoke with SSAs (mean $=0.98$ ) than smoke measured by AERONET from other tropical regions. Reid et al. (2005a) summarize SSA at $\lambda=670 \mathrm{~nm}$ for plumes observed in the 1990s by AERONET stations in the Amazon (0.93), the Brazilian cerrado (0.89), the Zambian savanna (0.84), and boreal forests in the US and Canada (0.935). After considering the ensemble of data at their disposal, Reid et al. 2005a recommend standard SSA at $\lambda=550 \mathrm{~nm}$ for smoke from wildfires in three broad biome types: savannas $(0.821 \pm 0.05)$, tropical forests $(0.85 \pm 0.05)$, and temperate and boreal fires $(0.88 \pm 0.05)$. However, Reid also notes wide variability in SSA even among the same region or fire type (e.g., Reid et al., 2005a, Table 2). Over Borneo, MISR retrieves a mean SSA of 0.98, significantly higher than Reid et al.'s (2005a) recommendation for tropical fires and somewhat higher than the AERONET-measured values for the Amazon. Gras et al. (1999) find similarly high SSAs for five Indonesian smoke plumes from 1997 (0.92-0.98), and Eck et al. (2003) find SSAs of 0.99 from Moldovan fires. Both studies attribute these bright aerosols to the predominance of smoldering fires fueled by peat. Additional fire data suggest that the SSA of smoke from smoldering fires ranges as high as 0.99 , significantly higher than the SSA from flaming or mixedphase combustion (Reid et al., 2005a, Sect. 2.4). Note that since most fires contain a mixture of smoldering and flaming combustion, "smoldering fires" are largely but not exclusively fueled by smoldering combustion. Smoldering itself produces no black carbon; hence, smoldering fires have a greater ratio of bright organic carbon aerosols to dark black carbon aerosols (Reid et al., 2005b, Table 2; Christian et al., 2003), which originate from peripheral flaming combustion (J. Reid, personal communication, 2012). However, organics can quickly coat black carbon aerosols, resulting in more hygroscopic internally mixed particles (Martins et al., 1998). Overall, observations of smoldering fires have generally yielded much higher SSAs than observations of flaming fires.

A majority of Borneo smoke plumes originate from peat forest regions, both in our dataset (Tosca et al., 2011, Fig. 1), and in previous observations (Page et al., 2002). Peat fires have a high ratio of smoldering to flaming combustion (Christian et al., 2003), and may contain significant amounts of sulfur which can produce bright, hygroscopic sulfate aerosol after combustion (Eck et al., 2003). Therefore, the high SSA observed in Borneo smoke plumes is largely consistent with primary emissions and secondary particle formation from smoldering peat fires, along with hygroscopic 
growth and brightening of these particles. Sampling biases may also influence our results because as mentioned above, SSA is not retrieved at pixels with optical depth $>2.5$. However, considering only plumes with valid SSA retrievals at all pixels yields a median single-scattering co-albedo (1-SSA) $10 \%$ lower than the median co-albedo for all plumes, which indicates that thick dark plumes are undersampled. Another reason why MISR-retrieved SSAs reported here exceed previous ground-based and in situ SSA measurements in the same region (Gras et al., 1999) may be that MISR preferentially samples the plume top (rather than the interior or bottom), where particles have experienced the most aging.

The down-plume evolution of single-scattering albedo is also of interest because it is one indicator of particle growth, formation, and coagulation processes. SSA in Borneo plumes peaks at 0.99 for $x=0$ and $x=0.65$, and reaches its minimum value (0.96) near $x=0.25$ and $x=0.9$ (Fig. 6f). A case study of South African smoke finds a SSA increase of 0.04 after $2.5 \mathrm{~h}$ and 0.06 after $5 \mathrm{~h}$ (Abel et al., 2003). This is consistent with qualitative trends in many previous studies (see e.g., Reid et al., 2005a, Sect. 2.4) and with an observed increase of 0.06 for smoke several days old (Reid et al., 1998). The 0.03 SSA increase we observe mid-plume occurs over an estimated elapsed time of $1.5 \mathrm{~h}$, a brightening rate consistent with Abel et al.'s results. Although the bright particles near the origin of the mean Borneo plume (Fig. 6f) may be contaminated by undersampling thick (optical depth $>2.5$ ) dark hydrophobic smoke, the plume origin (i.e. $x<0.1)$ is brighter than down-plume regions no matter how the plumes are screened. Moreover, any undersampling of thick dark plumes should lessen down-plume as the smoke disperses enough to permit optical retrievals. Particle coagulation in the first few minutes after emission (Hobbs et al., 2003) could brighten the plume near the origin if coagulation increases the number concentration of particles with sizes comparable to visible wavelengths, i.e. near $0.5 \mathrm{mi}-$ crons (e.g., Hansen and Travis, 1974). However, Hobbs et al. observe such coagulation over just $5 \mathrm{~min}$, whereas we observe darkening over the first 40-60 minutes.

The composite trend of SSA down-plume evolution that emerges (Fig. 6f, h) is a brightening from $x=0.2$ to $x=0.75$ followed by a darkening thereafter. Whereas most of the literature previously discussed is consistent with this midplume brightening, the darkening near the plume end has not been reported before, and must be reconciled with the near-constant behavior of optical depth from $0.3<x<1.0$ (Fig. 6b, d). If the darker SSA near the plume end were due to contamination by the underlying surface albedo as the plume disperses and thins, then one would expect optical depth to decrease near the plume end as well. This is not observed, though it may be the case that ground-feature contamination biases optical depth upward as well. Such a possibility is unfortunately very difficult to assess given our dataset. Since the digitized plume features and ends are sub-gridscale relative to the $17 \mathrm{~km}$ MISR retrieval grid, another possibility is that these sub-gridscale features interact unevenly with optical depth and SSA retrievals.

The halos visible in composite plots of SSA, top-ofatmosphere reflectance, and optical depth across all plumes (Fig. 6a, e, i), as well as similar halos in height (not shown), may result from the temporal evolution of plume shape. As plumes age, dispersion increasingly dominates over downplume transport, resulting in more circular plumes with a higher width-to-length ratio, higher SSA, and lower optical depth. Aged plumes increasingly resemble smoke clouds, which in comparison to smoke plumes have significantly greater areas and altitudes (Tosca et al., 2011), lower mean co-albedos (0.01 vs. 0.02$)$, and greater median length to width-ratios (1.02 vs. 0.24$)$, as well as $25 \%$ greater TOA reflectances. Additionally, smoke clouds exhibit substantially greater mean optical depth than smoke plumes (1.17 vs. 0.70 ). This does not imply that plumes continue to grow optically thicker for days and weeks, because smoke clouds incorporate multiple aged plumes as well as unsampled plumes and smoke of indiscernable origin, which may be optically thicker than average. The coagulation and lifting of smoke plumes into larger smoke clouds has important implications for local air quality (Davies and Unam, 1999) and for regional climate (Tosca et al., 2010).

As discussed in Tosca et al. (2011), Borneo smoke plumes have similar, though somewhat (within $\sim 100 \mathrm{~m}$ ) lower heights, relative to the surface and the atmospheric boundary layer, as plumes from North America (Val Martin et al., 2010) and from Alaska (Kahn et al., 2008). Smoke clouds and other regions of aged smoke reside significantly higher than their plumes of origin (e.g., McKendry et al., 2011; Paris et al., 2009; Guan et al., 2010; Tosca et al., 2011). In Borneo smoke plumes, relative and absolute height initially decrease down-plume before increasing toward the plume end (Fig. 7b,c). Such a dip in plume height was observed before in large, high plumes in Alaska, though the changes in height were much larger (Nelson, et al., 2008). This data suggests that this mid-plume dip is a common feature of smoke plumes, occurring even in lower plumes such as plume 1 , 2001 , which has a median height of only $460 \mathrm{~m}$ but nevertheless exhibits a dip in height in the middle and an increase in height towards the end (Fig. 7a). The height increase after the dip is consistent with older smoke lifting as the planetary boundary layer expands during the morning hours before the Terra overflight at 10:30 a.m. LT (Tosca et al., 2011). It is also consistent with settling of superheated air parcels from the fire that sink to their level of neutral buoyancy after overshooting it during injection, and then mixing with the environment.

The ages of Borneo smoke plumes are lognormally distributed with a median of $2.8 \mathrm{~h}$ (Fig. 10a). Note that these are the ages of the smoke furthest downwind for plumes with a discernable origin: once the origin of smoke becomes unclear, the "plume" is no longer sampled in our database, but its smoke remains in the environment, where it can contribute 
to a smoke cloud. Moreover, the plume age is distinct from the fire age, since the fire may persist for several days (Giglio et al., 2006b), but the plume is only discernible until it becomes too tenuous due to dispersal. Application of a technique similar to ours to estimate age of North American smoke plumes from 2002 and 2004-2007 yields a median age of $2 \mathrm{~h}$ (Val Martin et al., 2010). In the absence of evidence for different diurnal cycles of in Borneo and Central America, there is no reason to expect the $\sim 0.7 \mathrm{~h}$ lag in Terra overflight times between Borneo and Central America to bias either age estimate. The $0.3 \mathrm{~h}$ standard error of our estimate indicates that most of the $\sim 0.8 \mathrm{~h}$ disparity in plume age arises from intrinsic differences between the plume populations. As discussed above, the age disparity is consistent with greater fuel loads and fire emissions (van der Werf et al., 2006, Fig. 4) and more persistent, smoldering peat-fueled fires in Borneo than in North America. A study of Siberian smoke events finds ages ranging from 1 to 13 days with mean 5.5 days (Paris et al., 2009), an order of magnitude greater than ages obtained here. However, these smoke events are not associated with a source fire, and in some cases are located thousands of kilometers from the nearest active fires, so we would classify them as smoke clouds, not plumes (Tosca et al., 2011). The Siberian smoke clouds observed closest to an active fire had the lowest age (1 day), closer to our findings.

Biomass burning plumes from Borneo have geometric, optical, and age properties distinct from smoke plumes originating in other regions, even other tropical regions. Plume height is similar across a wide variety of regions: plumes from tropical forests in Central America and Indonesia are only slightly lower than those from boreal forests in Alaska and North America, and temperate forests in North America. However, plumes originating from tropical Central America are considerably shorter than those from Borneo. This indicates that fire persistence, fuel load, local meteorology, and the diurnal cycle of fire emissions play roles in determining the extent of tropical biomass burning plumes. Also, sampling bias from the late morning overflight time in Borneo likely explains part of the discrepancy in length between Borneo and Central American plumes. Additionally, plume length varies significantly across different biome types, such as tropical forest, boreal forest, or grassland (Val Martin et al., 2010). SSA is significantly higher for Borneo smoke plumes than for plumes originating from other tropical forest fires, possibly due to the smoldering nature of peat fires prevalent in Borneo and the high relative humidity of its maritime climate. Plume age is significantly greater in Borneo than in North America, which again may be attributed to differences in fuel loads, types and fire persistence. In summary, the heights, lengths, optical properties and lifetime characteristics reported for tropical biomass burning plumes on three continents are dissimilar and distinct from the same characteristics of wildfire plumes from the extratropics.
Plume properties examined here for the first time include the distributions of length, width-to-length ratio, area, plume density, and age, and the relation between wind speed and plume width. Length, width, area, and age are all well characterized by lognormal distributions. Wind speed predicts little of the variation in plume width, no matter how width is defined. Plume length is a good predictor of plume area, exponentially over the entire domain in Eq. (9) and linearly for lengths between 15 and $140 \mathrm{~km}$ in Eq. (10). The land-surface effects and radiative forcing of smoke plumes depend upon their area, which may be estimated from their length using Eqs. (9) or (10), and their lifetime, which follows a lognormal distribution (Fig. 10a). Modeling studies that require a realistic representation of plume density can scale our empirically based density parameterization Eq. (11) by an assumed plume length. While the distribution of length is affected by the overflight-time sampling bias described above, plume shape and density should not suffer the same magnitude of bias. Therefore, this parameterization is a plausible, empirically accurate shape for a prescribed stochastic distribution of tropical biomass burning smoke plumes. Plumes have associated radiative and air quality effects whose area of impact can now be included in mesoscale meteorological models, without requiring full knowledge of fire ignition, physics and behavior. As discussed in Sect. 5 below, the PDFs and parameterizations derived here are based on Borneo, and modelers should make appropriate adjustments before applying them to regions with different fuel types, interannual and diurnal fire emission cycles, and meteorological circulations.

\section{Conclusions}

Previous studies highlight the need for understanding the effects of open biomass burning on the global carbon budget and regional climate and air quality (e.g., van der Werf et al., 2006; Tosca et al., 2010; Davies and Unam, 1999; Henderson et al., 2008). Recent studies have applied fire and smoke detection algorithms to MODIS and MISR observations to characterize the seasonal and interannual behavior of fires and their associated plumes at global and regional scales (Nelson et al. 2008; Val Martin et al., 2010; Tosca et al., 2011). Using the same data sources as these three studies, we characterize a broader variety of physical and optical properties of tropical biomass burning plumes, including not only the ensemble mean and distribution of all properties (length, width, area, shape, optical depth, single-scattering albedo, and age), but also the intra-plume evolution of optical properties and height. Borneo smoke plumes in our database have a mean length $41 \mathrm{~km}$, a width $27 \%$ of their length, and an orientation largely influenced by prevailing southeasterly winds. While our observed length may be upwardly biased by the interaction of Terra's overflight time with the strong diurnal cycle of Borneo fires, we expect that the orientation and plume width results are representative of all Borneo 
smoke plumes. Optical properties are consistent with smoldering peat fire emissions which contain a larger fraction of organic carbon than emissions from non-peat fires. Downplume trends in optical depth and single-scattering albedo are consistent with aging, hygroscopic growth and nucleation. We provide a parameterization of plume density and distributions of plume length and width that can be used to model plume extent in lieu of knowledge of source fire dynamics. We also provide a distribution of plume age, which to our knowledge is the first such distribution reported for biomass burning smoke plumes. Intercomparison of our results with previous studies shows that the shape, height, optical depth, and lifetime characteristics reported for tropical biomass burning plumes on three continents are dissimilar and distinct from the same characteristics of wildfire plumes from the extratropics.

Potential users should be aware of the limitations and biases in the parameterizations we develop based on MISR imagery. Our work incorporates all plumes identified in Borneo during 2001-2009. This period includes substantial interannual variability, such as four dry (El Niño) and five wet years. The plume shape, size, and age PDFs we derive are most characteristic of plumes from peatlands during dry years, and are based only on plumes sampled during MISR's latemorning overflight time. Given the strong afternoon peak in the diurnal cycle of Borneo fire counts, our database may preferentially represent older, and thus longer, plumes. Subsampling our database for other fuel types, or meteorological conditions (e.g., wet years) would lead to different PDFs. However, this initial work gives researchers the first-order geometric and lifecycle characteristics of the plumes seen on Borneo by MISR. Mesoscale meteorological models can use this information to prescribe plumes with these empirical PDFs as a statistically accurate alternative to the more difficult task of predicting the shapes and ages of Borneo-like plumes.

We performed an initial characterization of the geometry and reflectance of tropical biomass burning smoke plumes seen by MISR and originating primarily from the peatlands of Borneo in the dry season during ENSO years. Longer timeseries of more frequent, sensitive, and spatially expansive observations are needed to build a smoke plume property database that better samples plumes with a strong diurnal cycle, of large optical thickness, from other (especially non-peatland) source regions and environmental conditions. Polar orbiting satellite-based retrievals of plume geometry and optical properties are subject to cloud contamination and overflight-time sampling biases and are limited by the horizontal resolution of the imager, and yield properties more representative of the plume top than lower levels. The extent to which ground-based and in situ measurements can quantify these biases is limited by the harsh, unpredictable location of and conditions in the fire plume environment. Studies similar to ours in other biomass burning regions would illuminate the roles of biome type, local meteorology, terrain, fuel loads, precipitation, and local wind speed in determining plume length, shape, and area. Furthermore, such studies would establish the regional or global extent of phenomena we identify in Borneo plumes, such as the width-to-length ratio, the down-plume increase in optical depth, and the midplume dip in SSA and plume height. Lastly, the evolution and coagulation of smoke plumes into smoke clouds is worthy of further study because these clouds significantly impact regional climate and local air quality in high-burning years such as during ENSO (Davies and Unam, 1999; Tosca et al., 2011). While MISR only captures images at a particular time of day, a geostationary satellite would observe the uninterrupted temporal evolution of smoke plumes and formation and maintenance of smoke clouds.

Acknowledgements. The authors thank D. Nelson and D. Diner for help constructing and evaluating the plume database, and S. Capps for providing global wind data. Helpful comments from two reviewers greatly improved the quality of this manuscript. C. S. Z. appreciates support from NSF (ARC-0714088) and NASA (NNX07AR23G). M. G. T. received support from a NASA Earth and Space Science Fellowship (08-Earth08F189). J. T. R. acknowledges NSF (AGS-1048890) and NASA (NNX10AT83G) support. The data analyzed here are publicly available in a database of plume injection heights at http://misr.jpl.nasa.gov/getData/accessData/MisrMinxPlumes and the MINX plume digitizing tool is publicly available at http://www.openchannelfoundation.org/projects/MINX.

Edited by: S. Kloster

\section{References}

Abel, S. J., Haywood, J. M., Highwood, E. J., Li, J., and Buseck, P. R.: Evolution of biomass burning aerosol properties from an agricultural fire in Southern Africa, Geophys. Res. Lett., 30, 1783, doi:10.1029/2003GL017342, 2003.

Bond, T. C., Habib, G., and Bergstrom, R.: Limitations in the enhancement of visible light absorption due to mixing state, J. Geophys. Res., 111, D20211, doi:10.1029/2006JD007315, 2006.

Christian, T. J., Kleiss, B., Yokelson, R. J., Holzinger, R., Crutzen, P. J., Hao, W. M., Saharjo, B. H., and Ward, D. E.: Comprehensive laboratory measurements of biomass-burning emissions: 1. emissions from Indonesian, African, and other fuels, J. Geophys. Res., 108, 4719, doi:10.1029/2003JD003704, 2003.

Davies, S. J. and Unam, L.: Smoke-haze from the 1997 Indonesian forest fires: effects on pollution levels, local climate, atmospheric $\mathrm{CO}_{2}$ concentrations, and tree photosynthesis, Forest Ecol. Manage., 124, 137-144, doi:10.1016/S0378-1127(99)00060-2, 1999.

Davies, R., Horváth, Á., Moroney, C., Zhang, B., and Zhu, Y.: Cloud motion vectors from MISR using sub-pixel enhancements, Remote Sens. Environ., 107, 194-199, 2007.

Diner, D. J., Beckert, J. C., Reilly, T. H., Bruegge, C. J., Conel, J. E., Kahn, R. A., Martonchik, J. V., Ackerman, T. P., Davies, R., and Gerstl, S. A. W.: Multi-angle Imaging SpectroRadiometer (MISR) instrument description and experiment overview, IEEE T. Geosci. Remote, 36, 1072-1087, 1998. 
Duncan, B. N., Bey, I., Chin, M., Mickley, L. J., Fairlie, T. D., Martin, R. V., and Matsueda, H.: Indonesian wildfires of 1997: impact on tropospheric chemistry, J. Geophys. Res., 108, 4458, doi:10.1029/2002JD003195, 2003.

Eck, T. F., Holben, B. N., Reid, J. S., O’Neill, N. T., Schafer, J. S., Dubovik, O., Smirnov, A., Yamasoe, M. A., and Artaxo, P.: High aerosol optical depth biomass burning events: a comparison of optical properties for different source regions, Geophys. Res. Lett., 30, 2035, doi:10.1029/2003GL017861, 2003.

Field, R. D., van der Werf, G. R., and Shen, S. S. P.: Human amplification of drought-induced biomass burning in Indonesia since 1960, Nat. Geosci., 2, 185-188, doi:10.1038/ngeo443, 2009.

Fromm, M. D. and Servranckx, R.: Transport of forest fire smoke above the tropopause by supercell convection, Geophys. Res. Lett., 30, 1542, doi:10.1029/2002GL016820, 2003.

Giglio, L., Csiszar, I., and Justice, C. O.: Global distribution and seasonality of active fires as observed with the Terra and Aqua Moderate Resolution Imaging Spectroradiometer (MODIS) sensors, J. Geophys. Res, 111, G02016, doi:10.1029/2005JG000142, 2006a.

Giglio, L., van der Werf, G. R., Randerson, J. T., Collatz, G. J., and Kasibhatla, P.: Global estimation of burned area using MODIS active fire observations, Atmos. Chem. Phys., 6, 957974, doi:10.5194/acp-6-957-2006, 2006b.

Gras, J. L., Jensen, J. B., Okada, K., Ikegami, M., Zaizen, Y., and Makino, Y.: Some optical properties of smoke aerosol in Indonesia and Tropical Australia, Geophys. Res. Lett., 26, 1393-1396, 1999.

Guan, H., Esswein, R., Lopez, J., Bergstrom, R., Warnock, A., Follette-Cook, M., Fromm, M., and Iraci, L. T.: A multidecadal history of biomass burning plume heights identified using aerosol index measurements, Atmos. Chem. Phys., 10, 64616469, doi:10.5194/acp-10-6461-2010, 2010.

Hansen, J. E. and Travis, L. D.: Light scattering in planetary atmospheres, Space Sci. Rev., 16, 527-610, 1974.

Henderson, S. B., Burkholder, B., Jackson, P. L., Brauer, M., and Ichoku, C.: Use of MODIS products to simplify and evaluate a forest fire plume dispersion model for $\mathrm{PM}_{10}$ exposure assessment, Atmos. Environ., 42, 8524-8532, 2008.

Hobbs, P. V., Sinha, P., Yokelson, R. J., Christian, T. J., Blake, D. R., Gao, S., Kirchstetter, T. W., Novakov, T., and Pilewskie, P.: Evolution of gases and particles from a savanna fire in South Africa, J. Geophys. Res., 108, 8485, doi:10.1029/2002JD002352, 2003.

Kahn, R. A., Li, W. H., Moroney, C., Diner, D. J., Martonchik, J. V., and Fishbein, E.: Aerosol source plume physical characteristics from space-based multiangle imaging, J. Geophys. Res., 112, D11205, doi:10.1029/2006JD007647, 2007.

Kahn, R. A., Chen, Y., Nelson, D. L., Leung, F. Y., Li, Q., Diner, D. J., and Logan, J. A.: Wildfire smoke injection heights: two perspectives from space, Geophys. Res. Lett., 35, L04809, doi:10.1029/2007GL032165, 2008.

Liebmann, B., Bladé, I., Bond, N. A., Gochis, D., Allured, D., and Bates, G. T.: Characteristics of North American summertime rainfall with emphasis on the monsoon, J. Climate, 21, 12771294, doi:10.1175/2007JCLI1762.1, 2008.

Liousse, C., Devaux, C., Dulac, F., and Cachier, H.: Aging of savanna biomass burning aerosols: consequences on their optical properties, J. Atmos. Chem., 22, 1-17, 1995.
Miettinen J., Shi, C., and Liew, S. C.: Deforestation rates in insular Southeast Asia between 2000 and 2010, Global Change Biol., 17, 2261-2270, doi:10.1111/j.1365-2486.2011.02398.x, 2011.

McKendry, I., Strawbridge, K., Karumudi, M. L., O’Neill, N., Macdonald, A. M., Leaitch, R., Jaffe, D., Cottle, P., Sharma, S., Sheridan, P., and Ogren, J.: Californian forest fire plumes over Southwestern British Columbia: lidar, sunphotometry, and mountaintop chemistry observations, Atmos. Chem. Phys., 11, 465-477, doi:10.5194/acp-11-465-2011, 2011.

Nelson, D. L., Chen, Y., Kahn, R. A., Diner, D. J., and Mazzoni, D.: Example applications of the MISR INteractive eXplorer (MINX) software tool to wildfire smoke plume analyses, Proc. SPIE, 7089, 708909.1-708909.11, 2008.

Nelson, D. L., Averill, C., Boland, S., Morford, R., Garay, M., Thompson, C., Hall, J., Diner, D., and Camphell, H.: MISR Interactive eXplorer (MINX) v1.0 User's Guide, Jet Propulsion Lab, NASA, available from: http://www.openchannelsoftware. com/projects/MINX, last access: November 2011, 2009.

Page, S. E., Siegert, F., Rieley, J. O., Boehm, H. V., Jaya, A., and Limin, S.: The amount of carbon released from peat and forest fires in Indonesia during 1997, Nature, 420, 61-65, doi:10.1038/nature01131, 2002.

Paris, J.-D., Stohl, A., Nédélec, P., Arshinov, M. Yu., Panchenko, M. V., Shmargunov, V. P., Law, K. S., Belan, B. D., and Ciais, P.: Wildfire smoke in the Siberian Arctic in summer: source characterization and plume evolution from airborne measurements, Atmos. Chem. Phys., 9, 9315-9327, doi:10.5194/acp-9-9315-2009, 2009.

Reid, J. S., Hobbs, P. V., Ferek, R. J., Blake, D. R., Martins, J. V., Dunlap, M. R., and Liousse, C.: Physical, chemical, and optical properties of regional hazes dominated by smoke in Brazil, J. Geophys. Res., 103, 32059-32080, doi:10.1029/98JD00458, 1998.

Reid, J. S., Eck, T. F., Christopher, S. A., Koppmann, R., Dubovik, O., Eleuterio, D. P., Holben, B. N., Reid, E. A., and Zhang, J.: A review of biomass burning emissions part III: intensive optical properties of biomass burning particles, Atmos. Chem. Phys., 5, 827-849, doi:10.5194/acp-5-827-2005, 2005a.

Reid, J. S., Koppmann, R., Eck, T. F., and Eleuterio, D. P.: A review of biomass burning emissions part II: intensive physical properties of biomass burning particles, Atmos. Chem. Phys., 5, 799825, doi:10.5194/acp-5-799-2005, 2005b.

Reid, J. S., Xian, P., Hyer, E. J., Flatau, M. K., Ramirez, E. M., Turk, F. J., Sampson, C. R., Zhang, C., Fukada, E. M., and Maloney, E. D.: Multi-scale meteorological conceptual analysis of observed fire hotspot activity and smoke optical depth in the Maritime Continent, Atmos. Chem. Phys., 12, 2117-2147, doi:10.5194/acp-12-2117-2012, 2012.

Seinfeld, J. H. and Pandis, S. N.: Atmospheric Chemistry and Physics, John Wiley \& Sons, New York, USA, 880-957, 1997.

Tosca, M. G., Randerson, J. T., Zender, C. S., Flanner, M. G., and Rasch, P. J.: Do biomass burning aerosols intensify drought in equatorial Asia during El Niño?, Atmos. Chem. Phys., 10, 35153528, doi:10.5194/acp-10-3515-2010, 2010.

Tosca, M. G., Randerson, J. T., Zender, C. S., Nelson, D. L., Diner, D. J., and Logan, J. A.: Dynamics of fire plumes and smoke clouds associated with peat and deforestation fires in Indonesia, J. Geophys. Res., 116, D08207, doi:10.1029/2010JD015148, 2011. 
Val Martin, M., Logan, J. A., Kahn, R. A., Leung, F.-Y., Nelson, D. L., and Diner, D. J.: Smoke injection heights from fires in North America: analysis of 5 years of satellite observations, Atmos. Chem. Phys., 10, 1491-1510, doi:10.5194/acp-10-14912010, 2010.

van der Werf, G. R., Randerson, J. T., Collatz, G. J., and Giglio, L.: Carbon emissions from fires in tropical and subtropical ecosystems, Global Change Biol., 9, 547-562, 2003.

van der Werf, G. R., Randerson, J. T., Giglio, L., Collatz, G. J., Kasibhatla, P. S., and Arellano Jr., A. F.: Interannual variability in global biomass burning emissions from 1997 to 2004, Atmos. Chem. Phys., 6, 3423-3441, doi:10.5194/acp-6-3423-2006, 2006. van der Werf, G. R., Dempewolf, J., Trigg, S. N., Randerson, J. T., Kasibhatla, P. S., Giglio, L., Murdiyarso, D., Peters, W., Morton, D. C., and Collatz, G. J.: Climate regulation of fire emissions and deforestation in Equatorial Asia, P. Natl. Acad. Sci. USA, 105, 20350-20355, doi:10.1073/pnas.0803375105, 2008. 